\title{
INSTITUCIONALIZAÇÃO DO PLANO DE CONTAS APLICADO AO SETOR PÚBLICO: ANÁLISE DA PERCEPÇÃO DOS GESTORES E CONTADORES DE SANTA CATARINA
}

\section{INSTITUTIONALIZATION OF THE PLAN OF ACCOUNTS APPLIED TO THE PUBLIC SECTOR: AN ANALYSIS OF THE PERCEPTION FROM MANAGERS AND ACCOUNTANTS OF SANTA CATARINA}

0 artigo foi aprovado e apresentado no $7^{\circ}$ Congresso da Universidade Federal de Santa Catarina (UFSC) de Controladoria e Contabilidade e $7^{\circ}$ Congresso UFSC de Iniciação Científica em Contabilidade, realizado de 10 a 12 de setembro de 2017, em Florianópolis (SC).

\section{RESUMO}

O objetivo deste artigo consiste em analisar a percepção de gestores e contadores públicos acerca do processo de implantação do Plano de Contas aplicado ao setor público (PCASP) na Secretária de Estado da Fazenda de Santa Catarina (SEF-SC) sob a perspectiva da Teoria Institucional com ênfase na Velha Economia Institucional. A pesquisa é descritiva quanto ao seu objetivo, e utiliza-se de uma abordagem qualitativa para sua análise, tendo como instrumento de investigação questionários aplicados aos gestores e contadores, visando identificar como o processo de implementação do plano de contas foi planejado, codificado, incorporado, reproduzido e institucionalizado, totalizando uma amostra com 36 respondentes. Os resultados demonstram que houve planejamento para a execução do processo, a percepção dos usuários foi positiva acerca da melhoria das rotinas contábeis, não afetando a confiabilidade das informações e que o processo impactou em um salto de qualidade das informações produzidas pela contabilidade e sucedeu importantes alterações, tais como a melhoria das rotinas contábeis, enfoque do patrimônio público e foco no regime de competência. Os gestores e contadores enfatizaram como sugestão acerca de implantação de processos semelhantes: a elaboração de planejamento, com acompanhamento e monitoramento de sua execução, contando com a participação das pessoas impactadas pelas mudanças.

Palavras-chave: Plano de Contas Aplicado ao Setor Público. Teoria Institucional. Normas Brasileiras de Contabilidade Aplicada ao Setor Público

\begin{abstract}
The purpose of this article is to analyze the perception of managers and public accountants about the process of implementation of the plan of accounts applied to the public sector (PCASP) in the Secretary of State of Finance of Santa Catarina (SEF-SC) from the perspective of Institutional Theory with emphasis on the Old Institutional Economy. The research is descriptive regarding its objective, and a qualitative approach is used for its analysis, having as a research instrument questionnaires applied to managers and accountants, aiming to identify how the process was planned, codified, incorporated, reproduced and institutionalized, totalizing a sample with 36 respondents. The results show that there was planning for the execution of the process, the perception of the users was positive about the improvement of the accounting routines, not affecting the reliability of the information and that the process impacted on a quality jump of the information produced by the accounting, such as improvement of accounting routines, focus on public equity and focus on the accrual basis. The managers and accountants emphasized as a suggestion about the implementation of similar processes: the elaboration of planning, with monitoring and monitoring of its execution, counting on the participation of the people impacted by the changes.
\end{abstract}

Keywords: Account Plan Applied to the Public Sector. Institutional Theory. Brazilian Accounting Standards Applied to the Public Sector

\section{Ana Paula Theodoro}

Graduada em Ciências Contábeis pela Universidade Federal de Santa Catarina (UFSC). Contato: Campus Universitário Trindade, Centro Socioeconômico, Florianópolis, SC, CEP: 88040-900. E-mail: paulatheodoro18@hotmail.com

\section{Marcelo Inocêncio Pereira}

Graduado em Ciências Contábeis pela Universidade Federal de Mato Grosso do Sul (UFMS). Contador na Secretária de Estado da Fazenda (SEFAZ -SC). Contato: Rod. SC 401, Km 05, 4600 - BLOCO V Saco Grande II - Florianópolis - CEP 88.032000. E-mail: mpereira@sefaz.sc.gov.br

Cristiane Aparecida da Silva Mestre em Contabilidade pela Universidade Federal de Santa Catarina (UFSC). Especialista em Gestão Financeira e Gestão Contábil pela Universidade Estadual do Paraná (UNESPAR). Especialista em Gestão Púbica pela Universidade Tecnológica Federal do Paraná (UTFPR). Graduada em Ciências Contábeis pela UNESPAR. Contadora na Universidade Federal da Grande Dourados (UFGD). Contato: Campus Universitário Trindade, Centro Socioeconômico, Florianópolis, SC, CEP: 88040-900. E-mail: cristianedasilva@ufgd.edu.br

\section{Fabricia Silva da Rosa} Pós-doutorado em Contabilidade pela Universidade Federal de Santa Catarina (UFSC). Mestre e Doutora em Engenharia de Produção pela UFSC. Doutorado sanduíche em Contabilitad pela Universitat de València. Graduada em Ciências Contábeis pela UFSC. Professora adjunta da UFSC. Contato: Campus Universitário Trindade, Centro Socioeconômico, Florianópolis, SC, CEP: 88040-900. E-mail: fabriciasrosa@hotmail.com 


\section{INTRODUÇÃO}

As instituições públicas brasileiras estão passando por mudanças nos últimos anos, caracterizadas pelo uso de ferramentas contábeis capazes de expressar informações que servirão de base para consolidação de relatórios no setor público. Conforme apontado por Silva (2011), por meio da publicação e edição das Normas Brasileiras de Contabilidade do Setor Público (NBC TSP), o caminho para a uniformização dos procedimentos contábeis e o reconhecimento da contabilidade como ciência que estuda o patrimônio foi aberto.

Em 2008, o Ministério da Fazenda editou a Portaria nº 184 acerca das diretrizes a serem observadas no Setor Público e referente aos procedimentos, práticas, elaboração e divulgação das demonstrações contábeis, visando torná-las correspondentes com as Normas Internacionais de Contabilidade Aplicadas ao Setor Público (NBCASP), expressas pela International Public Sector Accounting Standards (IPSAS), elaboradas pelo International Federation of Accountants (IFAC), entidade responsável por elaborar as Normas Internacionais de Contabilidade.

Rosa (2013) ressalta que as referidas normas acima mencionadas, além de serem consideradas um marco conceitual, cuja introdução adveio- a partir de um cronograma de transição pelos entes subnacionais, como Estados e Municípios, além da própria União, respeitando-se um cronograma nacional, são reconhecidas como uma verdadeira revolução na contabilidade do setor público brasileiro. O Plano de Contas aplicado ao Setor Público (PCASP) seria adotado integralmente até o final de 2014, conforme estabelecido no cronograma de ações constantes no anexo l da portaria/STN 439, de 12 de julho de 2012.

Para Feitosa (2012), o PCASP tem como objetivo geral a redução de divergências conceituais e procedimentais, em prol da gestão fiscal e sua devida transparência, assim como respaldar os entes da Federação na racionalização de custos e no controle social. Na qual foi estabelecido o cumprimento de seus objetivos e a manutenção dos próprios controle de cada ente.

Tomando como ponto de partida a realização e concretização dessas mudanças pelas organizações, a Teoria Institucional, proposta por Burns e Scapens (2000), é o alicerce teórico capaz de compreendê-las. Para Frezatti, Rocha, Nascimento e Junqueira (2009), essa proposição teórica, proveniente da vertente da Velha Economia Institucional, prevê que a contabilidade deve ser tratada como uma instituição, que conduz suas próprias características conceituais.

Neste contexto Scott (2004), ressalta que ao verificar transformações organizacionais, que abrangem características do comportamento humano, como a determinação de novas regras, e modificação de estruturas organizacionais, a Teoria Institucional é eficaz no proposito de entender os resultados de tais mudanças. Cruz, Major e Scapens (2009) destacam que, de acordo com essa base teórica, as tais alterações devem ter um caráter prático e aplicado a organização.

Verticalizando a proposta desse trabalho, consta-se que tal processo de mudança se refletiu nas instituições públicas do Estado de Santa Catarina, entidades subnacionais, obrigada a executar os procedimentos de adoção do PCASP, a partir das NBCASP, inseridas pelo Manual de Contabilidade aplicado ao Setor Público (MCASP), e tais mudanças precisavam ser absorvido pelos sistemas de informação dos entes públicos, e no caso do Estado de Santa Catarina, pelo Sistema de Planejamento e Gestão Fiscal (SIGEF).

A partir das considerações acima, propõe o seguinte questionamento: qual a percepção dos gestores e contadores públicos acerca do processo de implantação do plano de contas aplicado ao setor público (PCASP) na Secretaria de Estado da Fazenda de Santa Catarina (SEF-SC)? Neste contexto, o referido artigo tem por objetivo analisar a percepção dos gestores e contadores públicos acerca do processo de implantação do plano de contas aplicado ao setor público (PCASP) na Secretaria de Estado da Fazenda de Santa Catarina (SEF-SC).

Para realização dessa pesquisa, usou como aporte teórico a Teoria Institucional com ênfase na Velha Economia Institucional, considerando a implantação do PCASP no SIGEF e o impacto de sua utilização com a mudança, das NBCASP permitindo o presente estudo auferir resultados, via questionários, os quais foram direcionadas a dois grupos de servidores públicos; aqueles que colocaram em prática (gestores), e os que foram impactadas com a sua implantação (contadores).

Esse estudo justifica-se em primeiro momento no fato que a Teoria Institucional é uma teoria relevante, quando e se tratando de explicar a adoção de inovações por "organizações institucionalizadas" (GODDARD, 2016). Nos últimos anos, a Teoria Institucional tem sido amplamente aplicada em estudos de contabilidade do setor público, exemplos incluem: Ezzamel; Robson; Stapleton e Mclean (2007) investigaram no Reino Unido; Gomes; Carnegie e Lima Rodrigues (2008) e Hopper e Major (2007) investigaram em Portugal; Modell (2007) pesquisaram na Suécia e Nor-Aziah e Scapens (2007) na Malásia. Apesar desse levantamento de países na Europa, America do Norte e Asia, Goddard (2016) destaca que poucos estudos foram baseados em países em desenvolvimento.

Em segundo na adoção das NBCASPs, que representam mudanças significativas nas práticas contábeis aplicadas ao setor público, ou seja, procedimentos contábeis como o PCASP, o registro de provisões, e de depreciação de bens que passarão a ser obrigatórios a partir de sua adoção (PICCOLI; KLANN, 2015); A partir da referida adoção, foi necessário estudar a recepção dos profissionais da Contabilidade nesses segmentos, como também analisar o impacto com relação à implementação do PCASP, possibilitando o presente estudo fazer uma correspondência viável das bases empíricas da Teoria Institucional e sua aplicabilidade no setor público brasileiro, onde está circunscrito um país em desenvolvimento, como também captar e coletar o discurso dos contadores a respeito do resultado e suas consequências na contabilidade pública. 


\section{REFERENCIAL TEÓRICO}

\subsection{Teoria Institucional e Processo de mudança nas Organizações}

Nas palavras de Guerreiro, Frezatti e Casado (2006) a Teoria Institucional é uma abordagem sociológica, onde a instituição é formada por rotinas e hábitos amplamente aceitos de forma incontestável, dando sentido a determinado grupo de pessoas; No entanto a Teoria Institucional apresenta três correntes fundamentais a saber: Nova Sociologia Institucional (NIS), Nova Economia Institucional (NIE) e Velha Economia Institucional (OIE), que apesar das origens e princípios filosóficos específicos, elas têm em comum a compreensão da referida instituição e seus desdobramentos internos (GUERREIRO, FREZATTI, PEREIRA, LOPES, 2005).

A vertente da NIE, segundo Almeida e Callado (2017), tem como papel fundamental estudar as transações provenientes da racionalidade e oportunismo, de modo que venham a esclarecer o procedimento tanto ao modus operandi dessas transações, como esclarecer o porquê de as organizações contarem com graus hierárquicos em seu organograma. A vertente, chamada OIE, parte do pressuposto de que um determinado núcleo econômico possui rejeição, e que devido a isso, ela se ocupa da análise comportamental de seus agentes, via normas e regimentos institucionais. Por fim, a NIS, conforme demonstrado por Scapens (2006), tem se preocupado com as equivalências entre as organizações, como também com a questão relacionada aos processos e pressões moldadores das instituições.

Para os fins aos quais se destinam o presente estudo, se destaca a OIE, que segundo Guerreiro et al. (2005), considera a instituição enquanto objeto passível de análise, e não os aspectos comportamentais dos tomadores de decisões, uma vez que o termo "instituição" está atrelado ao que Major e Ribeiro (2008) conceituam como "formas de pensar e fazer instituídas”, as quais, de maneira inconsciente ou automática, são aceitas pelos seus agentes sociais. De acordo com Major e Ribeiro (2008), ao levar em consideração essa etapa de mudança promovida pela OIE dentro das instituições, surgem novas instituições, caracterizadas pela emergência gradual, cuja consolidação diz respeito aos hábitos individuais e rotinas coletivas.

De modo genérico Major e Ribeiro (2008), ressaltam que, a OIE não acata os embasamentos de racionalidade individual, como também os referentes ao individualismo metodológico na análise do desenvolvimento e transformação dos sistemas sociais. Em contrapartida, os agentes econômicos atuam numa situação específica, onde há uma adequação das normas e valores partilhados aos comportamentos individuais, e os autores ratificam que a OIE defende o holismo metodológico, isto é, organizações e agentes existem em contextos complexos, cuja consideração global deve estar envolvida na análise.

Para Angonese e Lavarda (2017), o que interessa a OIE é o aspecto interno da organização, e a maneira de como as práticas de contabilidade gerencial se transformam, ou seja, quando existe consolidação com OIE, a pressão para a mudança é interna na organização. Neste contexto Guerreiro et al (2005) enfatizam que as instituições têm um conjunto de características e rotinas, conforme apresentado na quadro 1, muito embora as instituições tenham o objetivo de desempenho satisfatório e os gestores tenham consciência e responsabilidade por buscar os melhores resultados para desempenhar o seu papel no dia-a-dia, os gestores precisam conhecer quais rotinas e quando executa-las.

Quadro 1 - Conjunto das principais Características e Rotinas de uma Instituição

\begin{tabular}{|c|c|}
\hline Caráter Coletivo & $\begin{array}{l}\text { As instituições são estruturadas por meio de rotinas definidas por pensamentos formalizados e } \\
\text { aceitos por um determinado grupo. }\end{array}$ \\
\hline $\begin{array}{l}\text { Caráter de dar significado } \\
\text { ao comportamento } \\
\text { organizacional }\end{array}$ & $\begin{array}{l}\text { As instituições permitem aos indivíduos e grupos dentro da organização dar significado às suas } \\
\text { atividades de rotina. }\end{array}$ \\
\hline Caráter objetivo & $\begin{array}{l}\text { As instituições definem padrões de comportamento que são esperados de um determinado grupo } \\
\text { social. }\end{array}$ \\
\hline Caráter normativo & $\begin{array}{l}\text { As instituições geralmente definem regras estabelecidas para a organização, porém isso nem } \\
\text { sempre ocorre, pois existem regras que não são aceitas pelo grupo social. }\end{array}$ \\
\hline $\begin{array}{l}\text { Caráter de não } \\
\text { questionamento }\end{array}$ & Os membros do grupo aceitam a instituição de forma inquestionável. \\
\hline Caráter repetitivo & A instituição implica em hábito, rotina e, portanto, em repetição de ações. \\
\hline Caráter de estabilidade & $\begin{array}{l}\text { Existem instituições que possuem uma vida curta e outras, uma vida mais longa. Porém todas têm } \\
\text { um certo período de tempo em que são prevalecentes e, durante esse período de tempo, existe } \\
\text { estabilidade. }\end{array}$ \\
\hline Caráter de orientar ações & $\begin{array}{l}\text { Quanto mais ampla e profundamente uma instituição é aceita, mais provável é sua influência no } \\
\text { sentido de direcionar ações e resistir a mudanças. }\end{array}$ \\
\hline
\end{tabular}

Fonte: Adaptado de Guerreiro et. al (2005). 
Em um mundo complexo e de incertezas, hábitos e rotinas são imprescindíveis, as rotinas são hábitos formalizados e institucionalizados que incorporam comportamentos baseados em regras e as mesmas podem ser definidas como "os meios formais reconhecidos pelos quais as coisas deveriam ser feitas". (BURNS; SCAPENS, 2000, p. 6).

Segundo Paiva e Andrade (2013), um processo de mudança interna na organização causa um impacto não apenas na percepção dos membros que dela fazem parte, como também sugere uma nova interpretação da realidade, no tocante à relação com o que é externo à companhia. Moura, Lima e Ferreira (2012) destacam que a mudança mais significativa trazida pela estrutura do Plano de Contas Nacional está nas contas de resultado, passando a registrar os fatos modificativos, mais adequados aos fundamentos da doutrina contábil.

De acordo com Liszbinski, Kronbauer, Macagnan e Patias, (2014) a vertente da OIE teve o empenho de demonstrar que as modificações na economia eram provenientes da evolução cultural da sociedade, e que não é algo previamente estabelecido pelo raciocínio e comportamento dos agentes com relação ao que seria considerado o equilíbrio perfeito. Liszbinski et al. (2014) ressaltam que a implantação da OIE na estrutura organizacional da instituição reflete nos seus padrões contábeis e na rotina dos indivíduos, que consequentemente, necessitam estar adaptados às novas facetas que surgem, e que essa implantação reflete também na uniformização dos procedimentos contábeis.

A partir desse aspecto, Lavarda, Feliu e Palanca (2009) pesquisaram como se procedeu a substituição de um sistema de contabilidade gerencial (SCG) em pequenas empresas do setor mobiliária no período de abril a junho de 2007, e como as características deste processo comprometem (ou não) a institucionalização. Ao adotarem a perspectiva analítica da Teoria Institucional, considerando especificamente a Velha Economia Institucional, os pesquisadores chegaram, a conclusão, que houve uma influência positiva na institucionalização do SCG nos seguintes componentes: a) conhecimentos e habilidades dos agentes envolvidos na mudança; b) recursos de informática; c) formação do pessoal; d) baixa participação de especialistas externos em SCG; e) sistema de incentivos aos funcionários; f) relações de confiança; g) processo de planejamento e h) envolvimento do pessoal.

Guerreiro, Pereira e Rezende (2006) levaram em consideração os hábitos e rotinas estabelecidos na instituição, que vieram por meio do processo de mudança tanto no sistema de custo quanto no de preço em uma empresa comercial familiar de médio porte, ou seja, teve como eixo norteador o "antes" e o "depois" dessa empresa após a implantação da OIE, via pesquisa-ação. Os dados compilados pelos pesquisadores mostraram três efeitos: o primeiro diz respeito ao domínio da contingência ambiental, que na fase "antes" da empresa, tornavam ineficazes as práticas contábeis existentes. O segundo efeito mostrou a inconsistência dessa empresa em relação à maneira incorreta como as rotinas e os hábitos eram institucionalizados, e por fim, o terceiro efeito resultou na remodelação do gerenciamento, via estratégias de institucionalização.

Beuren, Souza e Feuser (2017) conduziram a sua pesquisa com enfoque no CSC - Centro de Serviços Compartilhados - de uma empresa localizada na região Sul do país, e puderam averiguar a consequência diretas e indiretas no setor da Contabilidade Gerencial (CG) dessa empresa; foi necessário efetuar necessárias modificações nos segmentos corporativos e estruturais (doravante atividades), e que a aplicação dessa subdivisão da Teoria Institucional promoveu modificações positivas nessa empresa. Após a análise e cotejo dos dados, os autores argumentam que esse estudo teve um respaldo positivo na CG e que o CSC dessa empresa proporcionou novas modificações no seu corpo organizacional, tanto no quesito de rotina como nos papéis gerenciais institucionalizados.

Junqueira, Louro, Bubach e Gonzaga (2017) analisaram os fatores de resistência à mudança do Sistema de Informações Gerenciais (SIG), em uma organização do poder judiciário brasileiro, utilizaram o estudo de caso, com o framework de Burns e Scapens (2000) e de Huy (2001). As analises foram realizadas nas estruturas e processos de TI recomendados pela legislação em vigor e sustentadas pela literatura no campo. Os resultados indicaram que as estruturas e processos de TI que deveriam compor o SIG da organização não estão totalmente institucionalizados, apesar da pressão coercitiva para a mudança.

Os autores ressaltaram o uso cerimonial de vários processos do SIG e concluíram que, se alta administração não exercer seu papel de coordenação e apoio ao processo de mudança e se não houver uma adequada capacitação dos servidores, dificilmente as regras tornar-se-ão hábitos e rotinas, ou seja, serão institucionalizadas. Junqueira et al (2017) enfatizaram que o trabalho contribui para o campo ao descrever como falhas no planejamento da mudança e/ou o desinteresse da alta administração, associado à falta de capacitação dos funcionários inibe a institucionalização de novas regras, mesmo quando essas são estabelecidas de forma coercitiva.

\subsection{Aspectos legais do Plano de Contas aplicado ao Setor Público}

A partir da edição da Lei de Responsabilidade Fiscal (LRF), em maio de 2000, o país passou a sofrer influência internacional, com adequações em suas normas contábeis segundo a vigência internacionais. Conforme salientado por Silva (2013), o processo de convergência ocorreu por meio da coordenação do Conselho Federal de Contabilidade (CFC), o qual, por meio da resolução CFC 1.103/07, criou o comitê gestor da convergência no Brasil, responsável pelo desenvolvimento de ações, como também pela promoção da interação das NBC com as Normas Internacionais, tais normas representam um primeiro passo rumo à convergência da contabilidade do setor público brasileiro aos padrões internacionais.

Nesse viés, as NBCASP justificam-se pela relevância em promover informações contábeis advindas dos entes públicos. Na acepção de Rosa (2013), a contabilidade pública poderá ser utilizada como fonte de informações pelos usuários, possibilitando uma análise comparativa das informações contábeis disponibilizadas nos diferentes níveis de governo. 
Neste sentido o respaldo para o estudo está na implantação do PCASP pelo SEF-SC, considerando que o mesmo caracteriza a estrutura básica da escrituração contábil, formada por um conjunto de contas antecipadamente estabelecido, o qual visa obter informações necessárias à elaboração de relatórios gerenciais e demonstrações contábeis, consoante as características gerais da entidade, assegurando a padronização dos procedimentos contábeis (MOURA; LIMA; FERREIRA, 2012).

Porém se o ente da federação adota o PCASP, então o MCASP, deve ser aplicado na integralidade. Desta forma, o cronograma estabelecido ficou regimentado da seguinte forma: "As Partes IV - Plano de Contas Aplicado ao Setor Público e V - Demonstrações Contábeis Aplicadas ao Setor Público deverão ser adotadas pelos entes, de forma facultativa, a partir de 2012 e, de forma obrigatória, até o término de 2014” (SILVA, 2013, p. 66).

De acordo com a $6^{\text {a }}$ edição do MCASP (2014), o PCASP representa uma ferramenta crucial, tanto para a consolidação das contas nacionais, quanto de instrumento para a adoção das normas internacionais de contabilidade, permitindo diversas inovações, tais como: segregação das informações orçamentárias e patrimoniais; classificação orçamentária, patrimonial e de controle e individualização dos registros.

O PCASP simboliza a reformulação de diversos procedimentos contábeis tais como: i) registro dos fatos que afetam o patrimônio público neste caso considerando o regime de competência, em que as variações patrimoniais aumentativas e diminutivas devem ser reconhecidas nos períodos a que se referem, sejam elas dependentes ou independentes da execução orçamentária; ii) registros de procedimentos contábeis de acordo com às normas internacionais, como provisões, créditos tributários e não tributários, estoques, ativos imobilizados e intangíveis;; iii) reavaliação, depreciação, exaustão e redução ao valor recuperável (impairment); iv) elaboração de estatísticas fiscais em padrões exigidos pelos organismos internacionais (MCASP, 2014).

\section{PROCEDIMENTOS METODOLÓGICOS}

Com o propósito de identificar o processo de institucionalização na implantação do PCASP no SIGEF, da SEF-SC, realizou-se uma pesquisa descritiva com abordagem qualitativa, onde a pesquisa fundamentou-se na Teoria Institucional com ênfase na Velha Economia Institucional. Como instrumento de coleta de dados, foi usado o modelo de questionário fragmentado e adaptado da pesquisa de Marassi, Rosa e Lunkes (2015), elencando as seguintes variáveis: a) codificação; b) incorporação c) reprodução e d) institucionalização.

Cabe ressaltar que essas variáveis são provenientes da teorização proposta por Burns e Scapens (2000) na análise dos processos de institucionalização. O questionário foi composto por afirmações objetivas e questões com respostas dissertativas. A mensuração das afirmativas objetivas do questionário foi feita por intermédio da escala likert de 5 pontos, cujas respostas podem ser: concordo totalmente, concordo parcialmente, nem concordo e nem discordo, discordo parcialmente, discordo totalmente. As respostas dissertativas, possibilitaram o ensejo de uma análise qualitativa.

O questionário foi elaborado em duas partes, com seis blocos cada uma, a partir de uma literatura que tratasse acerca da implantação de sistemas. A primeira parte do questionário englobou seis blocos (1 - Caracterização do respondentes dos órgãos do Estado; 2 - Quanto às mudanças gerenciais; 3 - Quanto à fase de codificação; 4 - Quanto à fase de incorporação; 5 - Quanto à fase de reprodução; 6 - Quanto à fase de institucionalização), estruturados da seguinte forma: 1, 2 e 6 direcionados à Diretoria de Contabilidade Geral (DCOG), os blocos 1, 4 e 5 foram destinados a equipe de Gerência de Contabilidade Centralizada (GECOC), e o bloco1e 3 foi aplicado à Gerência de Sistemas de Gestão Fiscal da Secretaria (GESIF).

A segunda parte do questionário, consiste em seis blocos (1 - Caracterização dos respondentes; 2 - Quanto a fase de codificação; 3 - Quanto a fase de incorporação; 4 - Quanto a fase de reprodução; 5 - Quanto a fase de institucionalização; 6 - Questões Complementares), foram direcionados aos envolvidos no processo de mudança pertencentes aos usuários (Contadores).

Os questionários foram encaminhados aos gestores e contadores do SEF-SC, por meio do dispositivo Google Docs, no período de junho a outubro de 2016. Em relação à população da pesquisa, caracterizada pelo conjunto de indivíduos que apresentam em comum determinadas características, neste sentido foram considerados os gestores e todos contadores devidamente ativos na função, totalizando um montante de 85 servidores, sendo que deste total, 36 responderam o questionário, caracterizando a amostra do estudo (MARTINS; THEÓPHILO, 2009).

A delimitação de pesquisa está relacionada com as respostas que venham a elucidar a forma utilizada pela SEF-SC com relação ao processo de implantação do PCASP no SIGEF, a participação dos usuários e dirigentes (top-down ou democrática).

\section{DESCRIÇÃO E ANÁLISE DOS RESULTADOS}

\subsection{Descrição e análise da percepção dos gestores de topo}

Neste tópico são analisadas as respostas obtidas da GESIF, GECOC e DCOG cujas perguntas procuraram entender a visão dos gestores do processo de mudança, para que, no conjunto das respostas dos demais respondentes, houvesse a evidenciação do contexto da implantação do PCASP em Santa Catarina.

No que diz respeito à caracterização do respondente e dos setores SEF-SC, o gestor da DCOG respondeu que é formado em Ciências Contábeis e Especialista em Contabilidade Pública, atua no Cargo de Contador da Fazenda há 
13 anos e que exerce a função de diretoria há 2,5 anos. Na assertiva acerca do motivo de se iniciar o PCASP à época, respondeu que o mesmo foi implantado no exercício de 2013, com vistas para que os entes da federação tivesses suas contas consolidadas, assim como também o PCASP permitiu um grau de comparabilidade, figurando também nas regras e procedimentos padronizados.

Quando questionado a respeito do papel da DCOG, esse gestor foi categórico ao dizer que esse setor teve a responsabilidade na implantação do PCASP, e que GCOC ficou incumbida da provisão do plano de contas e tabela de eventos, como também ficou responsável pela uniformidade tanto das unidades gestoras como dos registros contábeis.

Acerca da responsabilidade da DCOG e estrutura institucional, o Gestor respondeu que essa diretoria foi responsável pela implantação do PCASP, cuja estrutura está na Gerência de Contabilidade Centralizada, responsável pela manutenção do plano de contas e tabela de eventos, além da consolidação das unidades gestoras e orientação a conformidade dos registros contábeis.

Da DCOG seguiu-se para a GESIF, que responde pela manutenção e desenvolvimento do SIGEF. Estão dentro do organograma da GESIF, a diretoria a Gerência de Estudos e Normatização Contábil (GENOC), a Gerência de Informações Contábeis (GEINC) e Gerência de Contabilidade Financeira (GECF), sendo que a GECF tem o papel de registrar a arrecadação do Tesouro Estadual e os lançamentos da conta única do Estado. Ainda compondo o organograma, estão a Coordenação de Informações Fiscais, do Sistema de Informação de Custos de Santa Catarina, do Sistema de Informação e Controle de Obras Públicas e a Assessoria.

Quanto ao processo decisório, o responsável destacou que existe a participação e a atuação constante dos gerentes, coordenadores e assessores, com reuniões periódicas e aberta a sugestões de melhorias por todos os colaboradores para ideias e projetos. Com relação às mudanças gerenciais a DCOG, observou-se que o processo de implantação do PCASP teve início marcado pela atuação de um GT (grupo de trabalho) que se preocupou em tornar eficazes tanto a codificação das contas (de=para) quanto as rotinas contábeis e funções do SIGEF

O Gestor da DCOG também respondeu que atualmente o plano de contas do Estado está padronizado até o $5^{\circ}$ nível, o que pode ser observado também nas intermediações da Secretaria do Tesouro Nacional. Além disso, todos os poderes e órgãos do Estado de Santa Catarina estão integrados e contemplados nesse contexto, dado o fato que houve o menor impacto possível para os usuários, automatizando diversos procedimentos.

No que se refere à frequência de mudanças na DCOG, citou-se que um dos princípios da diretoria é a inovação constante, sempre em busca da automatização de processos, desburocratização e promoção da transparência. Citando alguns exemplos de inovação está o Cartão de Pagamentos do Estado (CPESC), que permite a realização de gastos com despesas urgentes e de pequeno vulto, além da constante evolução e atual relançamento do Portal da Transparência do Poder Executivo, e o desenvolvimento do Sistema de Informações de Custos.

O Gerente de Sistemas de Gestão Fiscal, cuja permanência no cargo de contador da Fazenda Estadual iniciou em 2012, sendo dois anos na função supracitada, deixou claro que os princípios necessários para a implantação do PCASP foram o planejamento da mudança, priorização da equipe e a disponibilidade de recursos financeiros para alteração do sistema.

Quando questionado acerca da alteração de rotinas vigentes, essa autoridade enfatizou que no momento do planejamento, vislumbrou- a possibilidade de alterações das rotinas executadas de maneira manual, com automatização pelo sistema em função de inteligência, inserida na programação no momento das ações executadas pelos usuários.

Também afirmou que não foi utilizado um modelo externo (de fora) da instituição nem contratada uma empresa de consultoria, pelo fato do Estado ter suas divergências contábil em relação às instituições privadas, e ter um sistema de contabilidade e controle diferenciado de qualquer empresa que poderia ser pesquisada. Além disso, afirmou que os demais Estados e a União também não tinham uma fórmula que pudesse ser adotada.

Em relação ao processo de implantação do PCASP no SIGEF, o gerente do GESIF comentou que o início dessa implantação partiu de um planejamento, em decorrência do vencimento dos prazos, e também de um GT que fez o de = para das contas, e orientou as mudanças de conceito. Também citou que foi realizada uma análise de todos os pontos de impacto no sistema, com o objetivo de minimizar o impacto na utilização pelos usuários, e dessa análise, foi dimensionado o quantitativo de horas de trabalho e custo das alterações pela empresa que realizava a manutenção evolutiva do sistema.

Consequentemente, ao seguir o cronograma, houve diversas entregas de alterações em ambiente de homologação durante o ano de 2012, com conferência pela equipe do grupo de trabalho e pela GESIF, sendo disponibilizado em ambiente de produção para utilização pelos usuários a partir da abertura do sistema na vigência do ano de 2013.

No que tange a compreensão da mesma pelos usuários, o referido gestor argumentou que foi um processo de estudo e aprendizado constante, e na época do planejamento, estava bastante claro para a equipe do grupo de trabalho, mas não exatamente para os demais contadores, que foram atualizados pela DCOG, e encorajados a estudar mais a fundo a partir da implantação. Por fim, afirmou que acredita que o novo modelo confere legitimidade, a partir do entendimento da importância da convergência das normas internacionais de contabilidade.

O Dirigente da GCOC, no cargo de contador da Fazenda Estadual há 07 anos, sendo dois anos e meio na função citada, discorreu que na percepção de envolvidos em relação às consequências da implantação do PCASP que o impacto foi mínimo concernentes aos usuários, pois o objetivo realmente era não gerar impacto relevante acerca de suas atividades.

Quanto à orientação normativa, citou que houve uma disseminação junto aos órgãos e entidades e que os contadores tiveram treinamento e sensibilização. Com relação ao planejamento e acompanhamento, declarou que se restringiu em orientações para que a implantação não gerasse prejuízo no processo de execução orçamentária desse exercício. 
No quesito da aceitação do modelo quanto a valores e crenças, o dirigente mencionou que, os membros da organização estavam cientes e incentivando a implantação do PCASP.

\subsection{Descrição e análise da percepção dos Contadores da SEF-SC}

Essa etapa consistiu em propiciar um questionário específico aos contadores da SEF-SC, coletando 33 respostas. Cabe notar que essa etapa da pesquisa consiste em apresentar o perfil dos respondentes e sua percepção acerca do processo de implantação do PCASP.

A partir das respostas obtidas, constatou-se que o tempo de distribuição dos contadores no exercício do cargo, ficaram entre os anos de 1987 a 2009, conforme figura 1.

Figura 1- Ano de Formação dos respondentes.

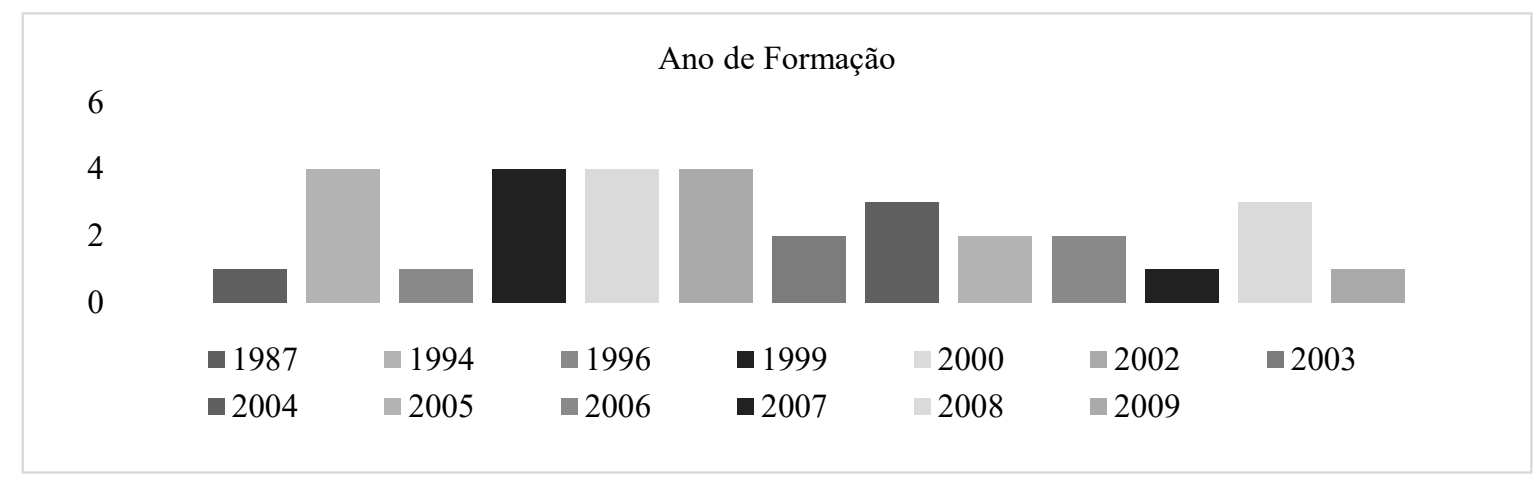

Fonte: dados da pesquisa (2017)

Esperava-se identificar a maturidade dos contadores dentro da profissão, considerando a época de formação, e constatou-se que o grupo é majoritariamente jovem, mas não inexperiente na profissão contábil. Outro fator crítico era o quanto de experiência no cargo o grupo teria para avaliar questões complexas, como a convergência das normas internacionais, o que ficou explicitado na figura 2.

Figura 2 - Tempo de trabalho na função

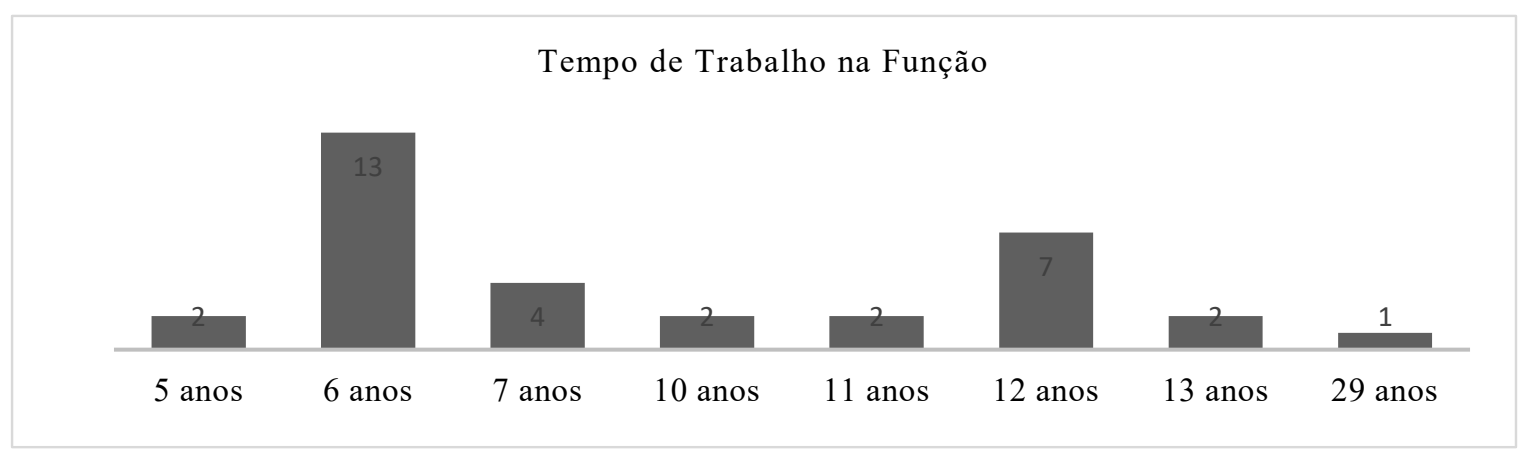

Fonte: Dados da pesquisa (2017)

Pode-se notar que a maioria do grupo já estava trabalhando como Contador da SEF-SC há, pelo menos, 6 anos, o que permitiu inferir que tinham experiência suficiente para responder os questionamentos levantados. No tocante às razoes que motivaram à implantação do PCASP, buscou-se analisar o que foi predominante para a implantação, e o resultado, conforme a figura 3 , demonstra que o aspecto legal e impositivo da padronização determinou a mudança. 
Figura 3 - Motivos para implantação do PCASP

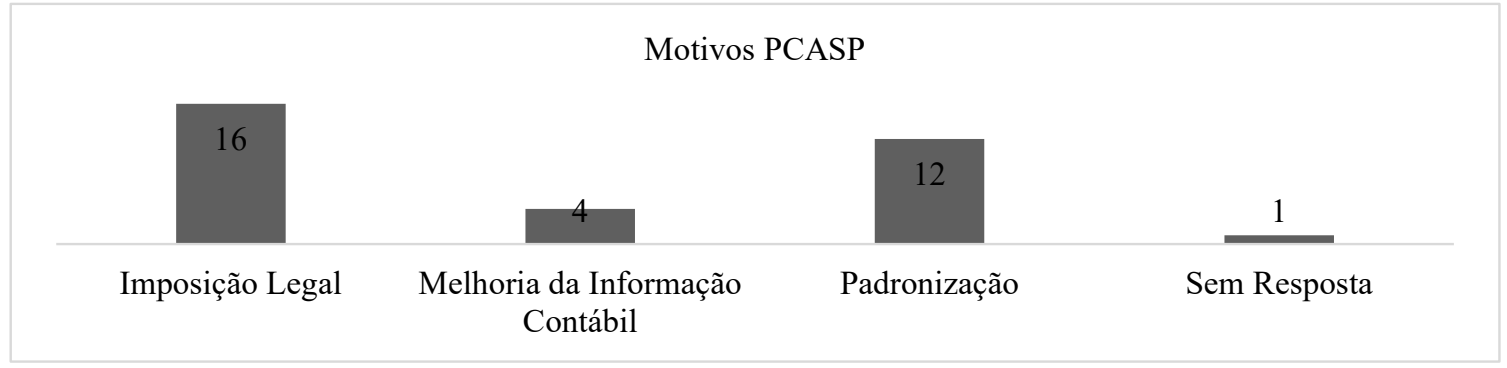

Fonte: Dados da Pesquisa (2017)

A respeito de circunstâncias possíveis de serem abordadas no processo de implementação do PCASP, foi imprescindível a identificação de outros aspectos ligados à própria mudança, e assim, 39\% afirmaram que haviam e/ou ainda há melhorias a fazer, como melhoria de rotinas e adaptação entre Estados e União, $27 \%$ responderam que foi feito o que estava ao alcance, e 33\% não souberam responder a esta pergunta.

Quanto ao Processo de Institucionalização - Codificação, duas perguntas foram feitas aos contadores com o objetivo de visando determinar aceitação e participação do grupo no processo, com respostas evidenciadas na figura 4.

Figura 4 - Processo de Institucionalização - Codificação

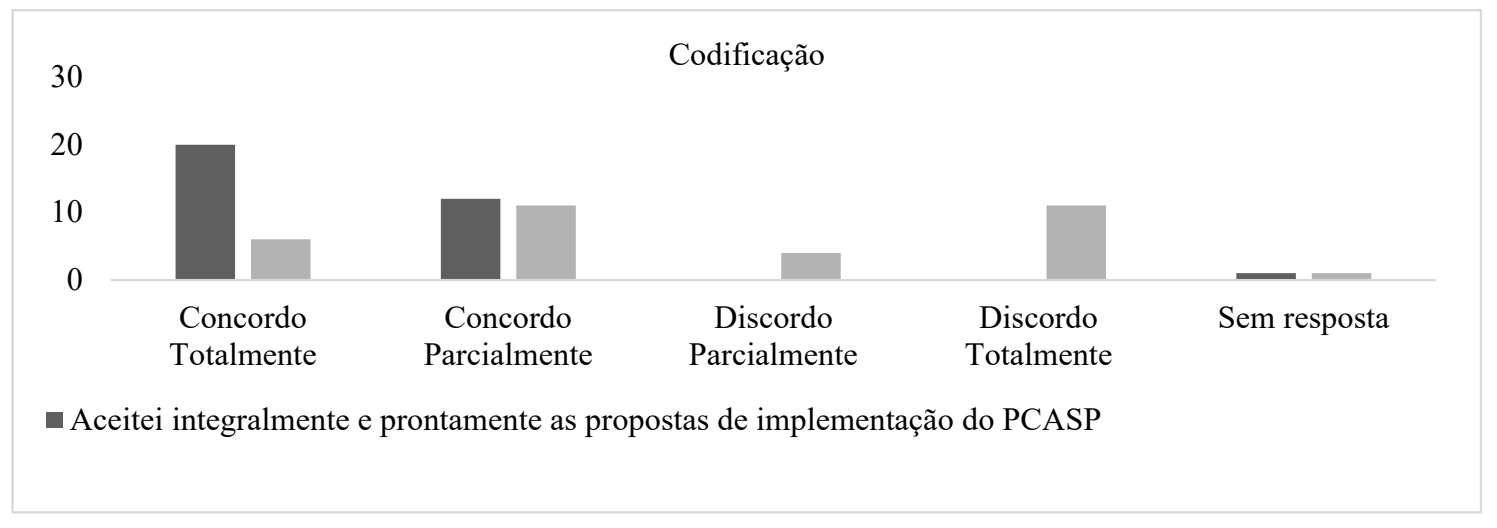

Fonte: dados da pesquisa (2017)

Observou-se que houve interação, ampla aceitação e participação da maioria do grupo na formulação da mudança, conforme as respostas indicaram. Quanto ao Processo de Institucionalização - Incorporação, foram feitas 3 perguntas aos contadores, cujo objetivo foi identificar a incorporação do processo de mudança, gerando um resultado expressivo nesse quesito, demonstrando o sucesso desse trabalho, tanto na execução quanto no monitoramento das mudanças, conforme figura 5 : 
Figura 5 - Processo de Institucionalização - Incorporação

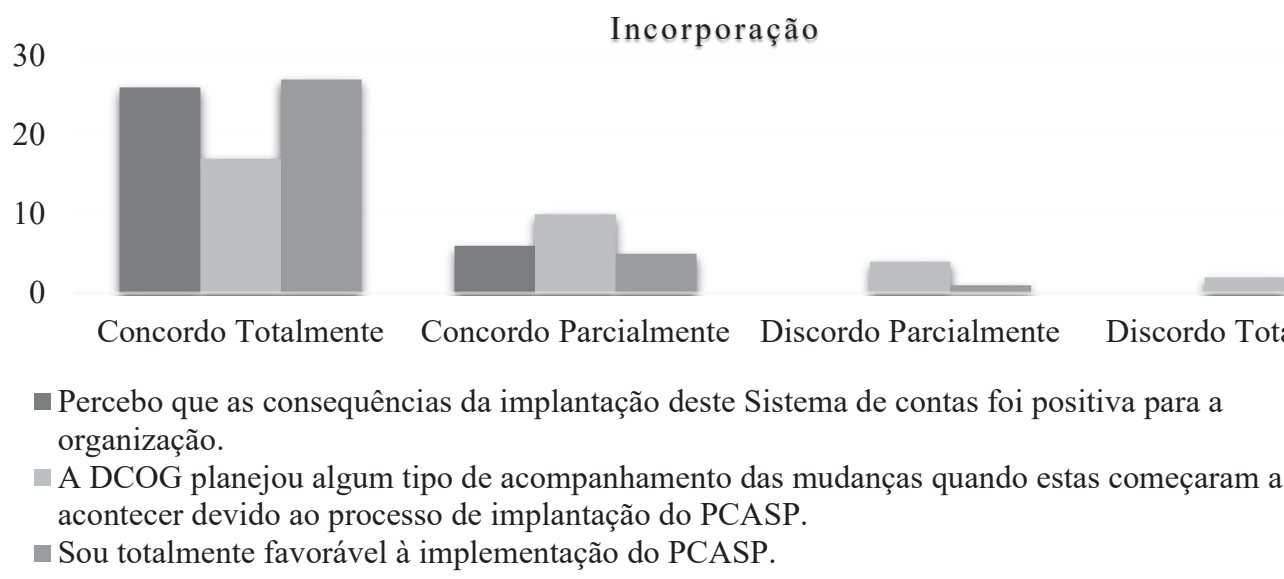

Fonte: Dados da Pesquisa (2017)

Quanto ao Processo de Institucionalização - Reprodução, 8 perguntas foram elaboradas, de modo que as respostas pudessem permitir identificar a forma como se deu a mudança pelos órgãos superiores e a recepção, com possíveis elogios, críticas ou sugestões vindas de seus subordinados.

Conforme ilustra a figura a seguir, os respondentes entenderam com certa facilidade a mudança, e, em sua maioria, admitiram não haver muitos questionamentos individuais ou de grupos quanto aos critérios de mudança. Nesse mesmo bloco, ampla maioria respondeu que a receptividade da mudança auxiliou no processo de melhoria das rotinas implementadas, embora a maioria também concorde que não houve monitoramento em relação a reprodução dessas rotinas.

Figura 6 - Processo de Institucionalização - Reprodução

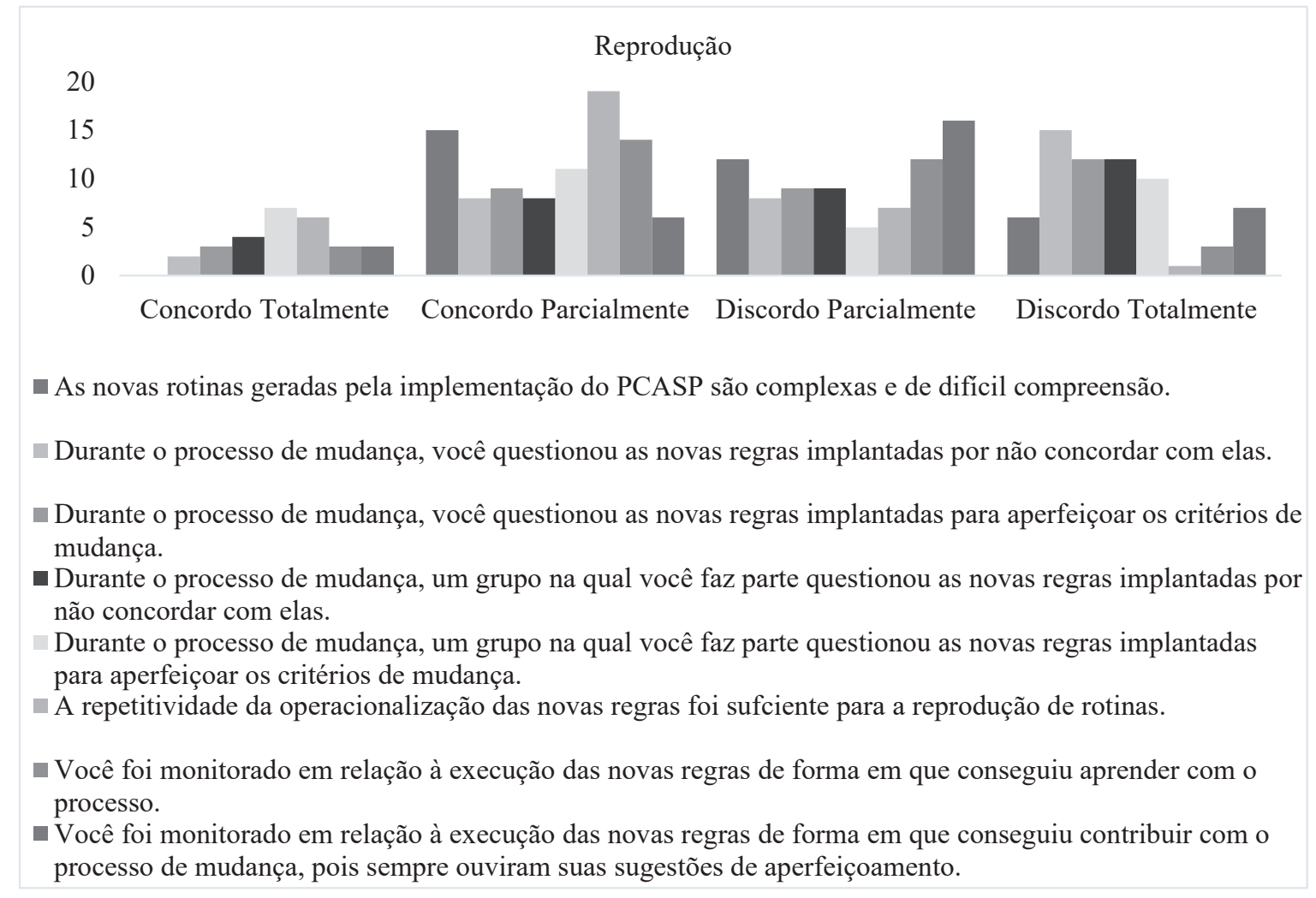

Fonte: Dados da Pesquisa (2017) 
No processo de institucionalização, foram elaboradas 3 perguntas, que tratavam do modo como foi absorvido pela instituição o novo PCASP. Após a coleta de dados, foi perceptível o sucesso, sendo os respondentes favoráveis a implantação, não havendo respostas discordantes a respeito do tempo necessário para funcionamento do novo PCASP, confiabilidade das informações e salto de qualidade com essa implementação, conforme figura 07.

Figura 7 - Processo de Institucionalização

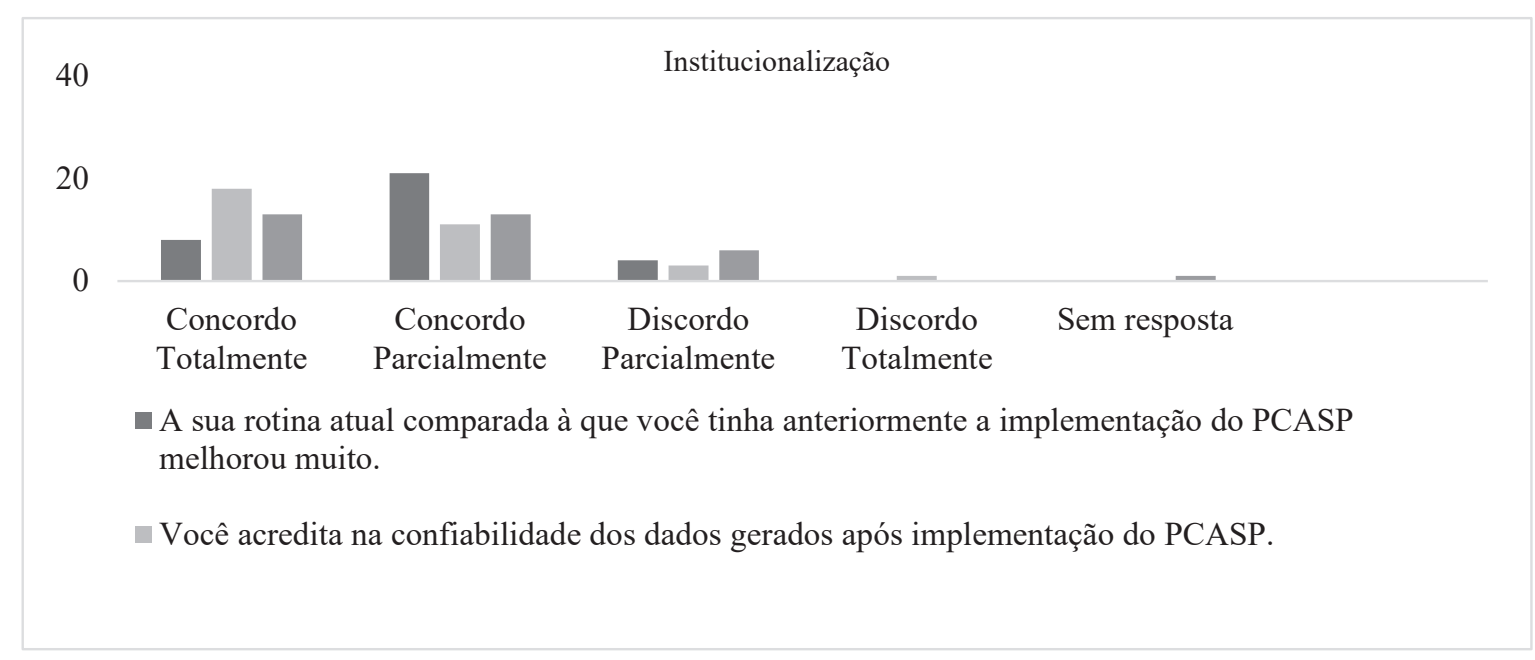

Fonte: Dados da Pesquisa (2017)

Nas questões complementares, precisou saber quais foram as principais alterações, valores e crenças da organização, dificuldades e adaptação à mudança, e as respostas foram as mais diversas, conforme figura 08.

Figura 8 - Principais Alterações

\begin{tabular}{|c|c|c|c|}
\hline \multicolumn{4}{|c|}{ Principais Alterações } \\
\hline $\begin{array}{c}\text { Mudanças em Rotinas } \\
\text { Contábeis }\end{array}$ & Enfoque no Patrimônio & $\begin{array}{l}\text { Foco no Regime de } \\
\text { Competência }\end{array}$ & Sem Resposta \\
\hline
\end{tabular}

Fonte: Dados da Pesquisa (2017)

A figura 8 destaca os efeitos da implementação do PCASP e representam a recepção e percepção dos servidores para com o sistema. Isso revela a amplitude das alterações ocorridas na implementação do PCASP, especialmente no regime de competência, enfoque no patrimônio e mudanças em rotinas contábeis, são muitos pontos de alteração. A respeito dos valores da organização, apenas 3 respondentes não compactuam com os demais em relação à inserção e ao efeito do PCASP.

Acerca das dificuldades encontradas, as respostas apontam para a questão de adaptação à nova rotina e a transgressão de paradigmas, que, por sua vez, vincula-se à percepção de realidade das pessoas. De acordo com os respondentes, acerca da adaptação ao processo de mudança pessoal, essa foi possível devido à disseminação do conhecimento, por meio de capacitações, treinamentos e estudos específicos da área de atuação, na qual houve atualização e tomada de decisões, necessárias aos profissionais envolvidos.

\subsection{Discussão do Resultados da Pesquisa}

Em relação ao bloco de assertivas referente a variável "codificação", 60,61\% das respondentes afirmaram que aceitaram integralmente a implementação do PCASP e 18,80\% afirmaram que participaram integramente da sua implantação. Acerca do bloco de assertivas concernente a variável “incorporação" 81,82\% concordaram que foram favoráveis a implantação do PCASP e 78,79\% afirmaram que as consequências da implantação do PCASP foram positivas e 51,52\% deles afirmaram que A DCOG planejou o acompanhamento das mudanças. 
Acerca do Bloco referente a variável "reprodução" nenhum respondente concordou que as rotinas geradas pela implantação do PCASP são complexas, somente 6,06\% afirmaram que questionou as novas regras a serem implantadas por não concordarem com elas. Concernentes a variável "Institucionalização" 63,64\% dos respondentes concordaram parcialmente que o tempo despendido foi suficiente para a implementação do PCASP e 54,55\% deles acreditam na confiabilidade dos dados gerados após a implementação do PCASP, e somente 9,09\% dos respondentes afirmaram que foram monitorados em relação a execução das novas regras.

Os resultados dessa pesquisa apontam que os responsáveis pela gestão e atuação nesses órgãos (os gestores e contadores) tiveram parte tanto na aceitação e formulação na mudança, assim como foi bem-sucedida a concretização desse planejamento, uma vez que os usuários tiveram satisfação em notar o menor grau de impacto, momento que se deve tanto à capacitação desses usuários, como também a percepção do aspecto legal dessa padronização.

Esses apontamentos vão ao encontro dos resultados de Lavarda et al. (2009). Embora a presente pesquisa tenha objetivo distinto, há harmonia com os autores supracitados, que tiveram como objeto de pesquisa o processo de interiorização da substituição de SCG em pequenas empresas, e concluíram que os fatores que influenciaram positivamente a institucionalização do SCG foram: os conhecimentos e habilidades dos agentes envolvidos na mudança, os recursos de informática, a formação do pessoal, a baixa participação de especialistas externos em SCG, o sistema de incentivos aos funcionários.

E também ao encontro dos resultados da pesquisa de Beuren et. al. (2017) que por sua vez, se ocuparam em estudar o impacto do CSC dentro da Contabilidade Gerencial (CG) de uma empresa também localizada no Sul do Brasil. Os resultados do estudo contribuíram para o desenvolvimento de novos papéis na Contabilidade Gerencial, sob o argumento que o modelo de CSC gerou novas regras e rotinas em toda a corporação, com implicações diretas e indiretas nos papéis gerenciais institucionalizados.

Porém os achados da presente pesquisa são contrários aos resultados de Junqueira et al. (2017), os autores investigaram à mudança do Sistema de Informações Gerenciais (SIG), em uma organização do poder judiciário brasileiro. Os resultados indicaram que as estruturas e processos de TI que deveriam compor o SIG da organização não estão totalmente institucionalizados, apesar da pressão coercitiva para a mudança. Os autores ressaltaram o uso cerimonial de vários processos do SIG e concluíram que, se a alta administração não exercer seu papel de coordenação e apoio ao processo de mudança e se não houver uma adequada capacitação dos servidores, dificilmente as regras tornar-se-ão hábitos e rotinas, ou seja, serão institucionalizadas.

Enfatiza-se que o estudo foi limitado a usuários da contabilidade, porém os mesmos não foram os únicos impactados, pois atualmente muitas pessoas inserem informações que são utilizadas pela contabilidade, já que o SIGEF é utilizado para registrar toda a execução orçamentária, financeira e patrimonial do Estado de SC., além de módulos gerenciais integrados, como contratos administrativos, transferências e precatórios, entre outros. Diante desse contexto, torna-se relevante estudo com os demais usuários que inserem tais informações para perceber o real impacto da implantação do PCASP em outros setores ou mesmo em outros órgãos do Estado de SC, e assim, destaca-se a necessidade de novas pesquisas e mais discussões acerca da implantação do PCASP.

\section{CONSIDERAÇÕES FINAIS}

O estudo objetivou analisar a institucionalização do processo de implantação PCASP na SEF-SC. Para tanto, foi elaborado questionários visando identificar como o processo foi planejado, codificado, incorporado e reproduzido na instituição, sob a percepção dos Gestores e Contadores da Fazenda Estadual.

Para concretizar essa pesquisa, foram enviadas perguntas aos atores desse processo, a saber: Diretoria de Contabilidade Geral, Gerências de Contabilidade Centralizada e de Sistemas de Gestão Fiscal, e aos Contadores da SEF-SC, totalizando uma população de 85 servidores, obtendo 36 respostas a qual caracterizou a amostra do estudo.

Face aos argumentos analisados, enfatiza-se que os conhecimentos, as habilidades dos agentes envolvidos na mudança, como também os recursos de informática quanto o planejamento para a implantação do PCASP dentro do cronograma estabelecido pelas normas, e a criação de um GT específico para esse fim, acompanhado de debate e sugestões entre os gerentes, coordenadores e assessores da SEF-SC, foram fatores primordiais para a implantação exitosa do PCASP na SEF-SC.

Levando em conta os fatos apresentados na pesquisa observou-se que o papel dos sistemas de informação, conforme enfatizado por Lavarda et al. (2009), é imprescindível para a formulação de qualquer mudança dentro de uma organização complexa, como é a SEF-SC., e as respostas do responsável por esse setor, demonstraram que haviam objetivos claros na mudança do processo, como o cumprimento do cronograma estabelecido e minimização do impacto para os usuários do sistema, que segundo o gestor responsável, foram cumpridos.

Ao analisar as respostas dos gestores das equipes de trabalho responsável pela implementação do PCASP, pode-se concluir que ela atingiu seu objetivo, reduzindo a complexidade do trabalho dos usuários em suas rotinas, assim como fez que com esses profissionais tivessem ciência de uma capacitação para lidar com essa ferramenta.

Em virtude dos argumentos apresentados acerca do processo de codificação, houve uma predominância das respostas quanto à aceitação e participação do processo de planejamento pelos usuários, além da percepção de sucesso na execução e acompanhamento das mudanças, dentro do processo de incorporação das mesmas. 
Com relação aos aspectos observados no processo de reprodução das mudanças, a pesquisa constatou a ausência de pouco questionamento acerca da recepção dos servidores perante ao modelo de mudança, fazendo coro com a visão de imposição legal tratada no item dos motivos. Por outro lado, a mudança do sistema foi muito bem aceita pela comunidade contábil, respaldando na melhoria das rotinas, embora não houvesse monitoramento nessa etapa.

A análise da percepção dos gestores de topo e dos contadores em relação ao processo de institucionalização revelou, por ampla maioria, que houve tempo suficiente para funcionamento do PCASP, e a confiabilidade das informações e salto de qualidade nas informações contábeis após esse processo.

Levando em consideração as questões complementares, concluiu-se que as principais mudanças citadas foram em rotinas contábeis, melhorando o funcionamento da máquina pública, no enfoque no patrimônio, melhorando a gestão, e o regime de competência, corolário da contabilidade. Também foi identificado que a mudança foi aderente aos valores e crenças da organização e que as dificuldades estiveram relacionadas com a adaptação às novas rotinas e a quebra de paradigmas, podendo ser considerado como hipótese da mudança conceitual.

Junqueira et al. (2017) enfatizam que mesmo em organizações altamente regulamentadas e fiscalizadas o isomorfismo coercitivo não é suficiente para que regras modifiquem hábitos e rotinas na organização. Nesse presente estudo as qualificações profissionais foram fundamentais para a institucionalização do PCASP, pois o mesmo não foi visto como uma adoção com transformação incremental ou rito cerimonial na contabilidade, alicerçado nos aspectos analisados a transformação foi revolucionária.

Dessa forma, as respostas proferidas pelos participantes indicaram uma ferramenta universal: o conhecimento adquirido, por meio de capacitações e treinamentos em prol de melhor envolvimento no ambiente de trabalho. Tais afirmações concernentes as capacitações e treinamento, indo ao encontro das ideais de Nguyen Huy (2001) pesquisador esse que prioriza o planejamento organizacional e capacitações dos servidores de modo que o retorno da capacitação possa ser devolvido à empresa, figurando como um degrau para o sucesso no processo de mudança organizacional, e reduzindo as resistências por parte dos demais envolvidos.

Para finalizar esse trabalho, face aos aspectos analisados e que foram também subsidiados de certa forma na revisão de literatura, fica como uma possível sugestão de pesquisa futuras a relevância de implantações de sistemas novos em um planejamento que seja monitorado e executado, contando com a participação ativa dos demais recursos humanos, pois foram as práticas consideradas válidas pelos respondentes no processo de implantação do PCASP na SEF-SC que tornaram isso possível.

\section{REFERÊNCIAS}

ALMEIDA, K. K. N.; CALLADO, A. L. C. Indicadores de Desempenho Ambiental e Social de Empresas do Setor de Energia Elétrica Brasileiro: uma Análise Realizada a Partir da Ótica da Teoria Institucional. Revista de Gestão, Finanças e Contabilidade, 7(1), 222-239,2017.

ANGONESE, R.; LAVARDA, C. E. F. Fatores para a implementação da mudança em sistemas de contabilidade gerencial. Enfoque Reflexão Contábil, 36(1), 139-154,2017.

BEUREN, I. M., SOUZA, L. R. B.; FEUSER, H. O. L. Implicações de um Centro de Serviços Compartilhados na Contabilidade Gerencial: Uma Abordagem Institucional. Revista Eletrônica de Administração, 23(3), 32-61,2017.

BRASIL. (2014). Manual de Contabilidade Aplicada ao Setor Público (MCASP) - 6 a Edição Parte Geral I, II, III, IV e V. Disponível em: http://www.tesouro.fazenda.gov.br/mcasp. Acessado em 10 de janeiro, de 2017

Portaria $\mathrm{n}^{\circ}$ 184, de 25 de agosto de 2008. Dispõe sobre as diretrizes a serem observados no setor público (pelos entes públicos) quanto aos procedimentos, práticas, elaboração e divulgação das demonstrações contábeis, de forma a torná-los convergentes com as Normas Internacionais de Contabilidade Aplicadas ao Setor Público. Disponível: http:// www.fazenda.gov.br/acesso-a-informacao/institucional/legislacao/portarias-ministerial/2008/portaria184. Acessado em 11 de janeiro, de 2017.

BURNS, J.; SCAPENS, R. Conceptualising management accounting change: an institutional framework, forthcoming. Management Accounting Research, Londres, v. 11, p. 3-25, 2000.

CRUZ, I., MAJOR, I.; SCAPENS, R. W. Institutionalization and practice variation in the management control of a global/local setting. Accounting, Auditing \& Accountability Journal, v. 22, n. 1, p. 91-117, 2009.

EZZAMEL, M., ROBSON, K., STAPLETON, P., MCLEAN, C. Discourse and institutional change: Giving accounts' and accountability. Management Accounting Research, 18(2), 150-171, 2007.

FEITOSA, J. P. Plano de contas aplicado ao setor público (PCASP) e sua obrigatoriedade a partir de 2013: estudo acerca da preparação e da expectativa, sob a ótica de profissionais de contabilidade pública de municípios. $74 \mathrm{f}$. Trabalho de Conclusão de Curso de Ciências Contábeis - Universidade Federal do Rio Grande do Norte, Natal, 2012.

FREZATTI, F.; ROCHA, W.; NASCIMENTO, A. R.; JUNQUEIRA, E. Controle Gerencial: uma abordagem da Contabilidade Gerencial no contexto econômico, comportamental e sociológico. São Paulo: Atlas, 2009.

GOMES, D.; CARNEGIE, G. D.; LIMA RODRIGUES, L. Accounting change in central government: the adoption of double entry bookkeeping at the Portuguese Royal Treasury (1761). Accounting, Auditing \& Accountability Journal, 21.8: 1144-1184, 2008. 
GUERREIRO, R., FREZATTI, F; CASADO, T. Em busca de um melhor entendimento da contabilidade gerencial através da integração de conceitos da psicologia, cultura organizacional e teoria institucional. Revista Contabilidade e Finanças - USP, Edição Comemorativa, p. 7-21, 2006

; FREZATTI, F.; PEREIRA, C. A.; LOPES, A. B. O entendimento da Contabilidade Gerencial sob a ótica da Teoria Institucional. O\&S. Organizações \& Sociedade, v. 35 ed. n. out/dez, p. 1-20, 2005.

; PEREIRA, C. A.; REZENDE, A. J. Em busca do entendimento da formação dos hábitos e das rotinas da contabilidade gerencial: um estudo de caso. Revista de Administração Mackenzie, v. 7, n. 2, p. 78-101, 2006.

HOPPER, T.; MAJOR, M. Extending institutional analysis through theoretical triangulation: regulation and activity-based costing in Portuguese telecommunications. European Accounting Review, 16.1: 59-97, 2007.

JUNQUEIRA, E.; LOURO, A. C.; BUBACH, C.; GONZAGA, R. P. Resistência à Mudança no Sistema de Informação Gerencial: Uma Análise da Institucionalização de Estruturas e Processos de TI em uma Organização do Poder Judiciário Brasileiro. Enfoque Reflexão Contábil, 36(2), 77-93, 2017.

LAVARDA, C. E. F., FELIU, V. M. R.; PALANCA, M. B. La Interiorización del cambio de un sistema Contable de Gestión en la pequeña empresa. Revista Contabilidade \& Finanças - USP, v. 20, n. 51, art. 7, p. 101-115, 2009.

LISZBINSKI, B. B.; KRONBAUER, C. A.; MACAGNAN, C. B.; \& PATIAS, T. Z. Conformidade no reconhecimento de ativos intangíveis: um estudo na perspectiva da teoria institucional. Revista Contemporânea de Contabilidade, v. 11, n. 24, p. 85-106, 2014.

MAJOR, M. J.; RIBEIRO, J. A teoria institucional na investigação em Contabilidade. Contabilidade e controlo de gestão: teoria, metodologia e prática. (Cap. 2, pp. 37-59). Lisboa: Escolar Editora, 2008.

MARASSI, R. B.; ROSA, F. S.; LUNKES, R. J. USALI: Processo de Institucionalização em uma rede de hotéis brasileira. In: XV Congresso Internacional de Contabilidade de Auditoria, Coimbra. XV Congresso Internacional de Contabilidade de Auditoria, 2015. v. 15, 2015.

MARTINS, G. A.; THEÓPHILO, C. R. Metodologia da investigação científica para ciências sociais aplicadas. São Paulo: Atlas, 2009.

MODELL, S.; JACOBS, K.; WIESEL, F. A process (re) turn?: Path dependencies, institutions and performance management in Swedish central government. Management Accounting Research, 18.4: 453-475, 2007.

MOURA, P. A. A.; LIMA, D. V.; FERREIRA, L. O. G. Plano de contas e convergência aos padrões internacionais: estudo comparativo entre as propostas dos governos brasileiro e espanhol. Contabilidade, Gestão e Governança, v. 15, n. 1, p. 3-16, 2012.

NGUYEN HUY, Q. U. Y. Time, temporal capability, and planned change. Academy of management Review, 26(4), 601-623, 2001.

NOR-AZIAH, A. K.; SCAPENS, R. W. Corporatisation and accounting change: The role of accounting and accountants in a Malaysian public utility. Management Accounting Research, 18.2: 209-247, 2007.

PAIVA, D. S.; ANDRADE, J. C. S. Resistências à mudança organizacional: análise do processo de implantação do sistema de gestão integrada no Senai-BA. Revista de Administração da UFSM, v. 6, n.3, p. 614-631, (2013).

PICCOLI, M. R.; KLANN, R. C. A. Percepção dos contadores públicos em relação às Normas Brasileiras de Contabilidade Aplicadas ao Setor Público (NBCASP). Revista do Serviço Público, 66(3), 425-448, (2015)

ROSA, M. B. Contabilidade do Setor Público. 2. ed. São Paulo: Atlas,. (2013.).

SCAPENS, R. W. Understanding management accounting practices: a personal journey. The British Accounting Review. v. 38, p. 1-30. (2006).

SCOTT, W. R. Institutional Ttheory: Contributing to a theoretical research program. Great minds in management: The process of theory development, p. 460-484., (2004).

SILVA, L. M. Contabilidade Governamental: Um Enfoque Administrativo da Nova Contabilidade Pública. 9. ed. São Paulo: Atlas. (2011.1)

SILVA, V. L. A Nova Contabilidade Aplicada ao Setor Público: Uma Abordagem Prática. 2. ed. São Paulo: Atlas. (2013). 